\title{
Bitcoin in Indonesia: Hedging or Investment Instrument?
}

\author{
William Wardoyo ${ }^{\mathrm{a}}$, Chaikal Nuryakin ${ }^{\mathrm{b}, *}$, \& Sean Hambalic \\ ${ }^{a}$ Magister of Economic Planning and Development Policy, Faculty of Economics and Business, \\ Universitas Indonesia \\ ${ }^{b}$ Department of Economics, Faculty of Economics and Business, Universitas Indonesia \\ ${ }^{c}$ Institute for Economic and Social Research, Faculty of Economics and Business, Universitas Indonesia
}

\begin{abstract}
Uncertainties might compel many investors to hedge by buying globally traded assets, such as Bitcoin, which has also been used as a means of payment in several countries. Bitcoin does not originate from any centralized authority and cannot entirely be controlled; therefore, Bitcoin usage might potentially pose issues to the monetary authorities within a country. This paper analyzes the effect of both global and domestic uncertainty on Bitcoin's demand in Indonesia. Our result suggests that Bitcoin is more used for hedging against both global and domestic uncertainties than it is used for hedging during episodes of Rupiah depreciation. Our findings also shed doubt on the effectiveness of monetary policies in regulating the highly-decentralized nature of cryptocurrencies investment markets. Lastly, the macroeconomic policy implications of our findings are also discussed.
\end{abstract}

Keywords: economic uncertainty; exchange rate; asset; hedging; Bitcoin JEL Classification: G12; D84

${ }^{*}$ Corresponding Address: Department of Economics, Faculty of Economics and Business, Universitas Indonesia; Jl. Prof. DR. Sumitro Djojohadikusumo, Kukusan, Kecamatan Beji, Kota Depok, Jawa Barat 16424. E-mail: chaikal.nuryakin@ui.ac.id. 


\section{Introduction}

The 2008 economic crisis engendered a widespread loss of confidence in the conventional financial system and its corresponding institutions. For example, in Europe, the widespread crisis has been found to reduce public confidence in the European Central Bank (Roth, 2009). Such growing distrust of the conventional financial system gave birth to developing a new form of money that possesses advantages over the current form of money that is in use. From this idea, virtual money arises and develops (Richter et al., 2015).

Virtual money can be loosely defined as a digitized form of money that is neither regulated nor controlled by its original developers, and it is widely used in specific communities (European Central Bank, 2012). The theoretical underpinnings for the emergence of virtual money are due to the development of new technology that helps trigger a structural transformation within the global economic landscape, including exchanging goods, services, and assets. The evolution of money and means of payment throughout history has contributed to a more efficient and secure exchange of goods and services (He et al., 2016).

Bitcoin is a form of decentralized money model, more widely known as the cryptocurrency ${ }^{1}$, brought forth into existence by Satoshi Nakamoto (a pseudonym) in 2008. Not backed by any commodities or municipal bonds, Bitcoin relies on a combination of cryptographic and peer-to-peer protocols (Meiklejohn et al., 2013). There have been two main ways to obtain Bitcoin, of which the first is to solve a computational puzzle to get a result in the form of Bitcoin. Such a process is called 'Bitcoin mining' ${ }^{2}$ (Kroll et al., 2013). Alternatively, one can also use real currency to purchase Bitcoin (Richter et al., 2015). A typical process of a Bitcoin use case can be laid out as follows: users of Bitcoin can send out funds to other users, first by providing combinations of her digital public address, private key (which is the password to her address) and the recipient's public address (Budish, 2018). Combining these three pieces of information then produces a cryptographic signature, which further encodes Bitcoin's amount to be transferred to the recipient. These individual transactions are publicly recorded in an accessible ledger widely known as "blockchain."3

\footnotetext{
${ }^{1}$ Cryptocurrencies are virtual currencies that use cryptography for their operations. Cryptocurrencies are stored in digital wallet software associated with cryptographic keys: (i) "public keys," which are used to encrypt data and function akin to an account number; and (ii) "private keys", which are needed for decryption and which function akin to a password to access the cryptocurrencies or a signature to authenticate transaction (He et al., 2016).

${ }^{2}$ Mining is the calculation of a hash of a block header, which includes, among other things, a reference to the previous block, a hash of a set of transactions, and a nonce (a 32-bit/4-byte field whose value is set so that the hash of the block will contain a run of zeros). If the hash value is found to be less than the current target (which is inversely proportional to the difficulty), a new block is formed and the miner gets 50 newly generated Bitcoins. If the hash is not less than the current target, a new nonce is tried, and a new hash is calculated. This is done millions of times per second by each miner (European Central Bank, 2012).

${ }^{3}$ Blockchain is the distributed ledger technology that is used to maintaining any records of all
} 
At the early phase of Bitcoin - specifically, right after Bitcoin was created - the first mining process was carried out by Nakamoto, the creator of Bitcoin itself, with 50 Bitcoin obtained from the mining process in January 2009 (Wallace, 2011). The opening of the first Bitcoin market, Mt. Gox, in 2011, marked the beginning of Bitcoin market development. During this early period, there was a group of people who spearheaded the use of Bitcoin. These early adopters were innovators and technology experts interested in developing and using Bitcoin in their respective business areas. Further, they led to the proliferation of Bitcoin-based financial services (e.g., investment and payment system).

Besides promoting Bitcoin's use in business sectors, other functions also began to develop - including its function as a hedging ${ }^{4}$ instrument. Its use in hedging activities was demonstrated in the 2012-13 Cypriot financial crisis, whereas the crisis exerted an immediate increase in demand and prices for Bitcoin. The volume traded on Mt. Gox rose dramatically during the period. However, the crisis also produced an unintended impact on Mt. Gox, in which it worsened the exchange infrastructure on the platform. The Bitcoin usage during the Cypriot financial crisis also triggered other widespread uses of the instrument, including as means of payment, for example, at one of the Universities in Cyprus, in which it received tuition payments using Bitcoin (Wolfson, 2015).

Bitcoin and other cryptocurrencies were initially designed to serve as a means of payment that can be used freely without any country restrictions. For example, Bitcoin did not originate from a particular country; hence, it can be categorized as a decentralized currency. However, cryptocurrencies' function as means of payment has been widely hampered after its ban in many countries (a famous example is Libra). Such progress compelled many to turn Bitcoin into a kind of speculative asset instead of its originally-intended function as a means of payment (Wolfson, 2015).

Bitcoin's side function as a hedging and investment instrument is inevitable, particularly amid the current condition of growing political and economic uncertainties. Within the last decade, for example, the rising tide of protectionism worldwide - as epitomized by the occurrences of Brexit and the rise of Donald Trump to the presidency, has exerted significant impacts on global economic conditions (e.g., trade war). Figure 1 plots the Global Economic Policy Uncertainty (GEPU) index trend from 2005 to 2020. The figure suggests that the index experienced a somewhat more intense fluctuation from mid-2012 to early 2018 compared to the earlier period. Although a decrease is observed from mid-2017 to early 2018, it is particularly noteworthy that since 2016, the index has remained well above 100. In some months, the index even reached a value of 200-300.

This substantially high GEPU index stands in contrast with earlier periods. Consider the 2005-2011 period, whereas it can be seen that the GEPU index had

\footnotetext{
transactions across the network, and smart contracts (Zamani \& Babatsikos, 2017).

${ }^{4} \mathrm{An}$ asset can be categorized as a hedge if that asset is negatively correlated to another asset on average (Bouri et al., 2017).
} 


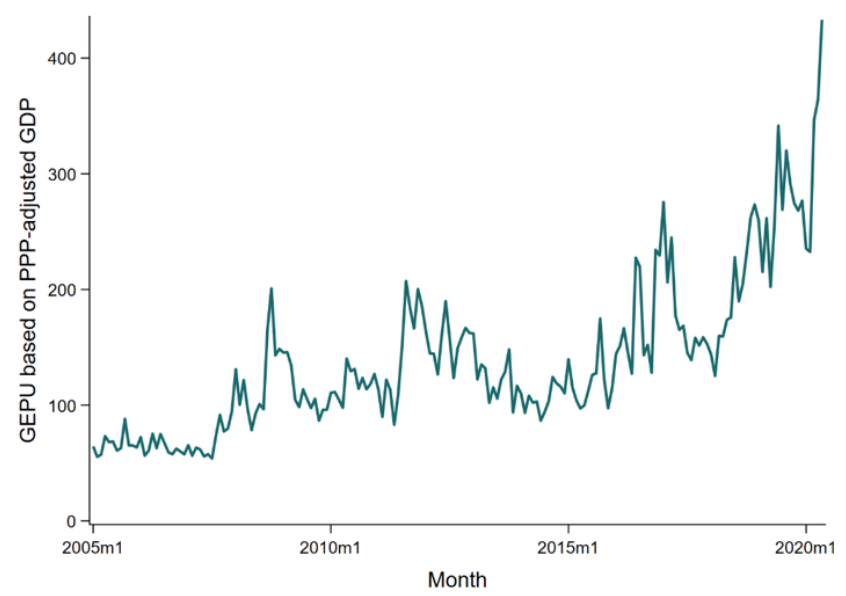

Figure 1: GEPU (Global Economic Policy Uncertainty) Index, 2005-2020

remained below 100 from 2005 to 2008. It has mostly remained above 100 since 2008, whereas a drastic increase is observed during the 2008 GFC (almost 200). Besides, from 2009 to 2011, the GEPU index had varied between 75 and 175. This piece of observation strengthens our conjecture that the global economic landscape is, indeed, experiencing increased uncertainty. The GEPU has been soaring since early 2020, reaching 433 in May 2020, reflecting the Great Lockdown recession triggered by the spread of novel COVID-19 around the world.

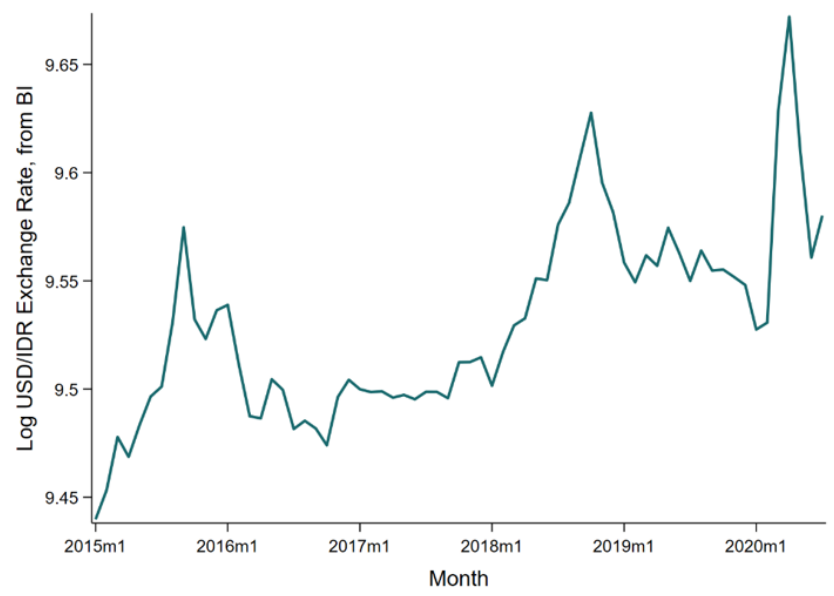

Figure 2: US Dollar against Rupiah Movements Source: Bank Indonesia, calculated by authors 
Furthermore, investors might also perceive increased domestic economic landscape risks due to Indonesia's exchange rate movements. Figure 2 implies an increasing trend of the USD IDR exchange rate from 2015 to 2020, meaning that Rupiah had experienced a depreciation of its value throughout the period. Such an increase in perceived risks might compel people to perform hedging using certain asset classes that can be traded globally. Traditionally, assets such as gold are commonly used as a hedging instrument. Empirical pieces of evidence suggest that gold also serves as a hedging instrument against US Dollar fluctuations (Reboredo \& Rivera-Castro, 2014) - as was the case for several Asian countries (India and Pakistan) during episodes of their currency's depreciation against the US dollar (Iqbal, 2017). Concerning uncertainty, gold also acts as a safe-haven under adverse circumstances (Jones \& Sackley, 2016).

However, recent evidence suggests that Bitcoin has also provided safe-haven alternatives for investors to turn to during uncertainty (Dyhrberg, 2016). Partly, its attractiveness arises from its nature of not being exposed to currency depreciations nor inflation, and therefore, immune to adverse macroeconomic conditions (Yu \& Zhang, 2020). It is important to note, however, that there can be other mechanisms that might be driving the correlation between Bitcoin and currency depreciations. For example, although local currency depreciation implies higher uncertainty, such depreciation against the US dollars can also entice investors to increase their stock of dollar-denominated assets - driving investors away from Bitcoin investments. Besides, Bitcoin also fulfils the fundamental property of being globally tradable, like gold. This has led many to use Bitcoin - or, in many cases, combined with gold - as a hedging instrument against US Dollar or stock index. In Indonesia's context, Figure 3 shows the increasing popularity of the non-conventional asset class. The trading volume of Bitcoin in Indonesia, proxied by LocalBitcoin, has been demonstrating an increasing trend since early 2016, indicating that the Indonesian market for Bitcoin, albeit still at its nascent stage, has been showing enormous potential.

Extant literature has remained inconclusive on Bitcoin's usage as a hedging instrument or investment asset. Its decentralized blockchain model has been particularly appealing to those desiring user autonomies over centralized control. Moreover, proponents of Bitcoin often cited increased payment efficiency. However, the less centralized authority also implies less monitoring and control, potentially leading to less effective policy-making. To its user, Bitcoin usage has often been surrounded by uncertainties about its legal basis. Many countries have decided to put an outright ban on its transactions, including in major countries like China. Indonesia is not unlike such countries - if not less clear - in its attempt to manage the proliferation of cryptocurrencies trading. Chang (2018) underscores the lack of clarity in Indonesia's national policy direction regarding cryptocurrency markets and the vague basis for the legal protections of parties in the transaction.

One example is the longstanding debate on whether virtual currencies might constitute assets or can be classified as personal property under the civil code. 


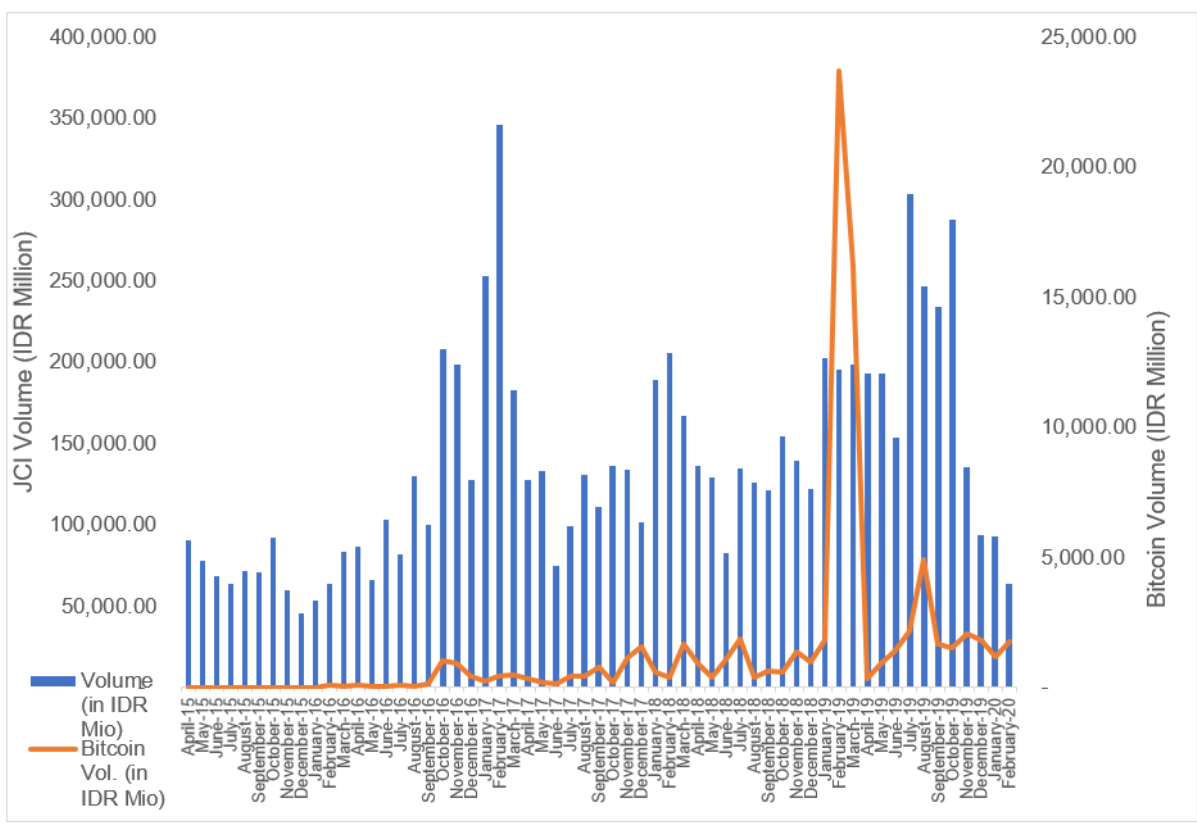

Figure 3: JCI vs. Bitcoin (LocalBitcoin) Trading Volume, 2015-2020 Source: Bloomberg \& CoinDance, compiled by authors

The detractors of such notion often argue that digital-based information cannot be classified as assets because it can be easily duplicated, copied and/or transmitted and hence do not satisfy the requirement to be classified as independently existing, identifiable and controllable (Chang, 2018). This has somewhat important ramifications for the transacting parties, particularly in the event where a virtual currency is not properly transacted - through fraud, mismanagement, etc. In such occasions, the victim can only rely on the terms and conditions of the contract as the measure of damages is legally uncertain. Moreover, as virtual currency cannot be considered as security (Chang, 2018), a fraud victim cannot be protected under securities laws to recover the arbitrage.

A breakthrough in the Indonesian regulatory ecosystem regarding cryptocurrencies came with the issuance of Badan Pengawas Perdagangan Berjangka Komoditi (Bappebti) (the Indonesian Commodity Futures Trading Regulatory Agency) Regulation No. 5/20195. In it, the authorities acknowledge the asset component within cryptocurrencies and further define crypto assets as an intangible commodity in the form of digital assets that use cryptography, peer-to-peer networks and a system of distributed ledger to organize the creation of new units, ver-

\footnotetext{
${ }^{5}$ The regulation was later amended through the issuance of Bappebti Regulation No. 9/2019.
} 
ify transactions and secure transactions without interference from other parties (Bappebti, 2019). Moreover, the regulation also contains provisions on requirements for conducting crypto asset exchange that include both capital and system requirements ${ }^{6}$. Although the use of cryptocurrencies as means of payment has remained barred, the issuance of the Bappebti Regulation undoubtedly presents its investors with renewed legal security.

As holding Bitcoin in Indonesia certainly comes with a risk as well as legal uncertainty, our paper attempts to analyze the use of Bitcoin as a hedging instrument in the Indonesian context. Notably, our study aims to study whether Bitcoin serves as a safe-haven during uncertainty in Indonesia. Implicitly, we study whether increased uncertainty propels a higher volume of Bitcoin trading. To the best of our knowledge, there remains little to no study of Bitcoin in Indonesia. Our study attempts to fill such a knowledge gap, providing policy-makers with relevant inputs on how to respond to the proliferation of cryptocurrencies in Indonesia. We also empirically study the relationship between the timing of monetary policy implementation and Bitcoin transaction volumes in the subsequent periods, shedding light on the effectiveness of monetary policies in regulating non-conventional assets, a prominent example of which includes cryptocurrencies.

We structure the rest of our paper as follows. The next section briefly summarizes relevant literature on Bitcoin and its nature as a hedging instrument. The third section lays out the explanation for variables and estimation methods used in this study. The fourth section presents the analysis result derived from the descriptive statistics and estimation results. The fifth section concludes.

\section{Literature Review}

\subsection{Economic Implications of Bitcoin}

The cryptocurrencies and the implication of its usage have only been studied intensively in the last five years. The digital currency relies heavily on the novel technology of 'blockchain,' which is most characterized by its decentralized nature (Catalini \& Gans, 2019; Cong \& He, 2019; Abadi \& Brunnermeier, 2018). Many studies have suggested that such decentralization provides benefits from network effects of shared platforms (Catalini \& Gans, 2019) while reducing rents extracted by third-party providers, and facilitating users' control over their data and privacy (Abadi \& Brunnermeier, 2018). Other studies have also shown that technology can promote efficiency through a reduction in verification costs

\footnotetext{
${ }^{6}$ Specifically, Bappebti 9/2019 maintains a minimum capital of IDR 500 billion, 50 billion, 25 billion, and 50 billion for Crypto Asset Exchange/Clearing House, Licensed Crypto Asset Physical Trader, Applicants of Crypto Asset Physical Trader, and Crypto Asset Storage Manager, respectively. Moreover, the regulation also mandates that the system used by the parties must be audited by Certified Information System Auditor (CISA).
} 
and networking costs (Catalini \& Gans, 2019); increased competition through a reduction in asymmetries of information (Cong \& He, 2019); and revolutionized corporate culture and governance (Yermack et al., 2017).

Through such efficiency-enhancing technological properties, cryptocurrencies have been dubbed to revolutionize and promote efficiency within existing financial markets (Brunnermeier et al., 2019). Cryptocurrencies are found to benefit citizens by diversifying options, thereby leading to higher consumer welfare (Dyhrberg, 2016; Chan et al., 2019). Studies have also linked the proliferation of private digital currencies - such as cryptocurrencies - to increases in local investment (Raskin et al., 2019). Raskin et al. (2019) argue that the government may gain from permitting, and indeed, nourishing private digital currencies within the local economy.

However, critics of cryptocurrencies have also shed light on the risks of broader digital currency adoption. Cong \& He (2019), for example, argues that the development of blockchain technology will result in a more dynamic equilibrium, wherein social welfare and consumer surplus might be lower than in the traditional world. Although the distribution of information - as made possible by the Blockchain technology - might promote lower verification costs, Cong \& He (2019) theoretically asserts that it might also foster collusion among sellers, primarily due to transparency on competitors's business-related information. Some also doubt the sustainability of these blockchain-based currencies. Budish (2018) points out that the Bitcoin business model is inherently expensive and particularly energy-consuming (Truby, 2018). It has to incentivize miners from ruining the system by ensuring that payments to these miners are large relative to the one-shot benefits of attacking such systems. Besides, Bitcoin has often been subject to various attempts at hacking and theft, posing serious security risks to its users and stakeholders (Yu \& Zhang, 2020). Due to Bitcoin's unstable nature and inherent risks, some dismiss Bitcoin as more characterizing speculative assets than a widely adopted currency (Yermack, 2013; Baur et al., 2018).

The utilization of cryptocurrencies, particularly Bitcoin, as an instrument rather than means of payment, has been widely debated in the extant literature. One particular avenue of such debates is whether investors have exhibited a "flight-to-quality" phenomenon to non-conventional assets, such as Bitcoin, during uncertainty periods. Panagiotidis et al. (2018) have documented that Bitcoin's demand rises significantly during periods of economic uncertainty - a finding consistent with that of Aysan et al. (2019). However, there have been controversies regarding its effectiveness as a diversifier, hedging, or safe-haven instrument (Bouri et al., 2017; Selmi et al., 2018). Some studies have suggested that Bitcoin is more potent as a diversifier instrument (Bouri et al., 2017; Wu et al., 2019). While others have shed light on the currency's effectiveness in hedging activities - mainly because its return is often uncorrelated and not affected by changes in traditional asset markets, such as that of stock, oil and gold (Chan et al., 2019; Aysan et al., 2019; Dyhrberg, 2016; Selmi et al., 2018; Cheng \& Yen, 2020; Bouri et al., 2017). 
Interestingly, other studies have empirically found evidence of Bitcoin's lack of performance as a hedging instrument (Smales, 2018; Klein et al., 2018; Gurdgiev \& O'Loughlin, 2020; Das et al., 2020; Wu et al., 2019). However, such seemingly contradictory results are unsurprising, as Bouri et al. (2017) have suggested that Bitcoin's performance as an investment asset might be contingent on differing market situations and ecosystems (Das et al., 2020). Also, Bitcoin's profitability as an investment asset has been strongly affected by the country's regulatory climate (Selmi et al., 2018). Therefore, a different reaction to the cryptocurrencies might also yield different investment results.

Although extant literature suggests that context is indispensable in the analysis pertinent to cryptocurrencies, to the author's best knowledge, there remains no study on the digital currency within Indonesia's context. Notably, our study investigates whether the rise in uncertainty, both in the global and domestic environment, compels people to trade Bitcoin in Indonesia. In other words, the study attempts to document the "flight-to-Bitcoin" phenomenon in the country. Perhaps our study is closely related to Yu \& Zhang (2020), which attempts to study the impact of several major global events on Bitcoin return. This study fills in the existing knowledge gap in Indonesia's context. It is in the hope of the authors that this study can inform policy-makers with the right information in their endeavor to formulate policies regarding cryptocurrencies.

\section{Methodology}

\subsection{Explanation of the Variables}

This study attempts to analyze the relationship between Bitcoin and uncertainty conditions by using regression methods. The dependent variable used in our model is the volume of Bitcoin trading in Indonesia. While existing studies often use the price or returns of Bitcoin as a measure, in our study, we opt for using its traded volume due to several reasons. First, the volume variable arguably proxies its demand more accurately because it measures the number of transactions occurring (both sales and purchases) within a specified period. Hence, an increase in volume directly implies an increase in the demand for the asset class. The second reason is that volume, instead of price or return, mitigates mismeasurement issues. For instance, although Bitcoin trading might be conducted on an Indonesian-based platform, this does not rule out that the platform might also be used by non-Indonesian citizens to conduct such exchange - thereby potentially misreporting the actual Indonesian demand. In addition, a study by Balcilar et al. (2017) empirically proves the adequacy of Bitcoin traded volume in predicting the value of its corresponding returns.

To explain variations in the demand for Bitcoin, we employ several independent variables. One variable we include in our regression model as the control variable is the Bitcoin price. As higher prices imply higher asset returns, it can be argued that higher Bitcoin prices lead to higher transaction volumes. Also, 
studies have documented the herd behavior phenomenon (Scharfstein \& Stein, 1990). Under certain circumstances, investors simply mimic the decisions made by their peers and, to some extent, ignoring substantial private information. This implies that high returns might exacerbate an exponential rise in transaction volumes as well. As such, we hypothesize that Bitcoin price exhibits a positive association with the volume being traded.

Another main variable is the Global Economic Policy Uncertainty (GEPU) index, a comprehensive index variable capturing global sentiments of uncertainty. The GEPU calculates a GDP-weighted average of uncertainty index of 20 countries, including Australia, Brazil, Canada, Chile, China, France, German Greece, India, Ireland, Italy, Japan, Mexico, the Netherlands, Russia, South Korea, Spain, Sweden, United Kingdom, and the United States. The GEPU index has also been used in prior studies discussing the impact of uncertainty of economic policies towards the demand for Bitcoin (Fang et al., 2019). The variable is used to observe significant relationships between global uncertainty and the demand for Bitcoin in Indonesia.

The USD/IDR exchange rate is also employed to observe the relationship between exchange rates and Bitcoin volume traded in Indonesia. The exchange rate itself is widely used to measure a particular asset's hedging ability, an example being gold. The exchange rate can also be used to provide rough depictions of domestic economic uncertainty. When viewed through this lens, it is expected that higher USD/IDR exchange rates (implying depreciation of IDR) will be associated with higher Bitcoin demand. However, a USD appreciation also implies higher returns on dollar-denominated assets, and this can potentially drive investors away from investing in Bitcoin. Therefore, the expected sign of the association between these two variables is ambiguous. A positive sign implies that Bitcoin has been used as a hedging instrument in the episodes of exchange rate depreciation, while a negative sign will imply that episodes of exchange rate depreciation compel investors to increase their dollar-denominated assets and thereby, reducing their Bitcoin investments.

The next variable is the gold variable - which can be assumed as a rival asset class for Bitcoin. Previous studies have often compared Bitcoin with gold in terms of its appropriateness as a hedging instrument, to the extent where Bitcoin was dubbed as the new type of gold by some of these studies (Dyhrberg, 2016; Klein et al., 2018; Smales, 2019). As extant literature suggests that gold exhibits substitutability with Bitcoin, we hypothesize that any gold return increase will reduce Bitcoin demand. The three variables mentioned above have been widely used in previous studies (Panagiotidis et al., 2018) with slightly different measures but the same type of variable.

We also include the Credit Default Swap (CDS) variable in our model, to serve as a proxy for domestic uncertainty. The CDS can be used as a proxy for domestic uncertainty because an increase in CDS value implies the increased demand for CDS, indicating the rise of economic uncertainty in the domestic economic landscape. We hypothesize that increased CDS value, implying a more uncertain 
domestic economic condition, will induce Bitcoin's demand. We employ this variable because it is generated by the market, directly measuring Indonesia's economic policy's uncertainty to further proxy domestic uncertainty.

To empirically study monetary policies' effectiveness in regulating the market for non-conventional assets, we also include additional dummy policy variables. Specifically, in this study, we focus on two major policies pertinent to cryptocurrencies that have been enacted over the past five years: (1) Bank Indonesia's (BI) policy that effectively precludes the usage of cryptocurrencies as a means of payment in Indonesia, which was formally implemented through the issuance of PBI No. 18/40/PBI/2016 on the Processing of Payment Transactions; and (2) Commodity Futures Trading Regulatory Agency's (Bappebti) policy that formally legalizes the trading of crypto assets conditional on the fulfillment of several requirements such as being based on distributed ledger technology, takes on the form of utility crypto and crypto-backed assets, being among the top 500 crypto assets in terms of coin market capitalization as well as several other clauses. The policy was formally implemented through the issuance of Bappebti's Regulation $5 / 2019$. As with traditional asset classes, practical policy implementations are reflected by observable effects on market activities. We hypothesize that policy implementations will exhibit significant associations on subsequent market activities, as proxied by transaction volumes in our case. We expect the PBI and Bappebti policy dummies to be negatively and positively (respectively) correlated with transaction volumes, as the former (the latter) limits (widens) the use of Bitcoin, thereby potentially resulting in lower (higher) asset values and transaction volumes. However, the not significant relationship between the dummy variables and transaction volumes casts indicative doubts on the effectiveness of implementing monetary policies in the attempt to regulate non-conventional asset markets.

\subsection{Regression Model}

$$
\begin{aligned}
\text { VOL }_{t}= & \beta_{1}+\beta_{2} * \text { BTCPrice }_{t}+\beta_{3} * \text { GEPU }_{t}+\beta_{4} * G O L D_{t} \\
& +\beta_{5} * \text { KURS }_{t}+\beta_{6} * \mathrm{CDS}_{t}+\beta_{7} * D_{\text {Investment }_{t}}+\beta_{8} * D_{\text {Usage }_{t}}+U_{t}
\end{aligned}
$$

$V O L_{t}$ in the equation above denotes the logarithmic value of Bitcoin trading volume in Indonesia at period $t$. BTCPrice ${ }_{t}$ denotes the logarithmic value of USDdenominated Bitcoin closing prices at period $t$. Meanwhile, GEPU $U_{t}$ indicates the Global Economic Policy Uncertainty Index (GDP-PPP adjusted) log values at period $t$. GOLD $D_{t}$ denotes log values of world gold prices per troy ounce at period $t$, and $K U R S_{t}$ indicates the log values of USD-IDR exchange rate at period $t$ - that is, the selling price of Rupiah against US Dollar during one particular time. The last variable in our model, $C D S_{t}$, indicates the logged values of CDS in Indonesia at period $t$. Our analysis includes both 6-month CDS as well as 12-month CDS values. 
Further, we also include two dummy policy variables, as indicated by $D_{\text {Investment }}$ and $D_{\text {Usage }_{t}}$ in the model above. The former indicates the post-period of the lifting of the Bitcoin investment ban by Bappebti in February 2019 (through the issuance of Bappebti Regulation No. 5/2019), while the latter indicates the post-period of Bitcoin transaction ban by Bank Indonesia in September 2016 (through the issuance of 18/40/PBI/2016). Finally, the $U_{t}$ indicates the error term of the model at period $t$.

The model will be estimated using a standard OLS procedure, wherein we will first test for the stationarity of the variables in the model. If stationarity is not satisfied, the model's variables will instead be reported in first difference values as opposed to its level values. Estimation results and their corresponding interpretations are reported in Section 4.

\subsection{Data Collection Method}

The study uses secondary monthly data for all of the variables included in our estimation model, whereas the observation spans five years, from January 2015 to June 2020. All in all, our observation amounts to 65 . The secondary data in this study were taken from various sources. The dependent variable in our model, the Bitcoin volume, was taken from the Bitcoin Charts website ${ }^{7}$. The website provides daily volume data on transactions conducted on the Indodax platform, the first and one of the most significant Bitcoin marketplace in Indonesia. It started off as an information website for cryptocurrency in 2013 (by the name of bitcoin.co.id), but then in 2014 it transformed into being the first trading website for cryptocurrency in Indonesia. Since then, its user base has been growing rapidly - amounting to nearly 2.1 million by mid- $2020^{8}$.

The daily data obtained from the website was then averaged into monthly frequency. Data on the USD-denominated Bitcoin prices were taken from the Coin Desk website. Similarly, we average the daily data into monthly frequency. In addition, data on gold prices were taken from the Federal Reserve Bank of St. Louis ${ }^{9}$, provided in monthly frequency, measured in US Dollars (per troy ounce).

The exchange rate data was taken from BI's website, which provides daily data on buy rates. Likewise, it was also averaged to form a monthly frequency data to ensure comparability among other variables. The Global Economic Policy Uncertainty (GEPU) Index was obtained from the Policy Uncertainty Index website $^{10}$. Lastly, daily CDS data for both 6-month and 12-month values were taken from the Bloomberg terminal database, which was then transformed into monthly frequency by taking its average over one month.

\footnotetext{
${ }^{7}$ https://bitcoincharts.com/.

${ }^{8}$ In addition to having the biggest user base of cryptocurrency investors in Indonesia, it is also the first Indonesian cryptocurrencies trading website that possesses two internationally-recognized certificates (ISO 9001: 2015 and 27001:2013).

${ }^{9}$ https: / / fred.stlouisfed.org.

${ }^{10}$ in monthly frequency (http:/ / www.policyuncertainty.com/global'monthly.html.)
} 


\section{Result and Analysis}

Table 1 presents the summary statistics for the variables used in our study. The trend for these variables is reported in section A of the Appendix. The summary statistics suggest that our dependent variable has experienced substantial monthly fluctuation from January 2015 to July 2020, indicated by the strikingly high max-min ratio of nearly 55 . Such a finding is not to our surprise, given the extreme volatility of Bitcoin trading reported by other studies (Baur \& Hoang, 2020). We do not observe the same level of variation among other variables.

Table 1: Summary Statistics

\begin{tabular}{lrrrrrr}
\hline \hline Statistics & $\begin{array}{r}\text { BTC Vol. } \\
(\text { BTC })\end{array}$ & $\begin{array}{r}\text { BTC Price } \\
(\text { USD })\end{array}$ & $\begin{array}{r}\text { GEPU } \\
(\text { Index })\end{array}$ & $\begin{array}{r}\text { GOLD } \\
\text { (USD/Troy Ounce) }\end{array}$ & $\begin{array}{r}\text { KURS } \\
\text { (IDR/USD) }\end{array}$ & $\begin{array}{r}\text { CDS } \\
(\text { Value })\end{array}$ \\
\hline Mean & 14905.67 & 4411.9050 & 197.23730 & 1264.8130 & 13786.7600 & 31.28597 \\
Min & 1231.50 & 233.5008 & 97.20697 & 975.4196 & 12579.1000 & 8.10500 \\
Max & 67288.21 & 14821.7300 & 433.20910 & 1777.0750 & 15867.4300 & 80.13000 \\
p50 & 11838.58 & 3663.1590 & 174.86760 & 1235.4720 & 13732.2300 & 25.66000 \\
SD & 11338.34 & 3982.6450 & 72.97037 & 157.4653 & 628.6322 & 17.87376 \\
\hline Obs. & 67 & & & & \\
Period of Obs. & January 2015-June 2020 & & & & \\
\hline
\end{tabular}

Figure 4 plots the (logged) market transaction volumes for Bitcoin on the Indodax platform. The graph suggests that the Bitcoin market has been experiencing a declining trend since its peak in early 2016. The market further plummets in June 2020, even reaching its 5-year lowest level in July 2020. Another interesting observation that can be inferred from the graph is the lack of evidence for strong observable effects from the two major market policies' enactment. Counter-intuitively, we observe a positive trend in the transaction volumes after implementing the BI ban (as indicated by PBI 18/40/2016 line on the graph). In contrast, no clear trend is observed in the aftermath of the issuance of Bappebti Regulation 5/2019. We further explore the relationship between the policy dummies and transaction volumes in the regression analysis below.

Before conducting the regression analyses, we observe the stationarity properties of our variables of interest. The graphical representations of the explanatory variables (in the Appendix) indicate a trend among these variables. We see a sharply increasing trend in (logged) Bitcoin prices, gold prices, and exchange rates, and on the contrary, a sharply decreasing trend is observed in CDS across the years - albeit it has been on the upward movement since March 2018. The GEPU variable, our main proxy for global uncertainty, exhibits a rather weak upward trend. To formally test these explanatory variables' stationarity, we then conduct the Augmented-Dickey Fuller (ADF) test, reported in Table A1 of the Appendix section. The test results suggest that the hypothesis that all of our variables possess unit root cannot be rejected, thereby indicating the presence of a non-stationarity problem in our variables. We include the trend variable to obtain more unbiased estimates in our model to address such stationarity issues. 


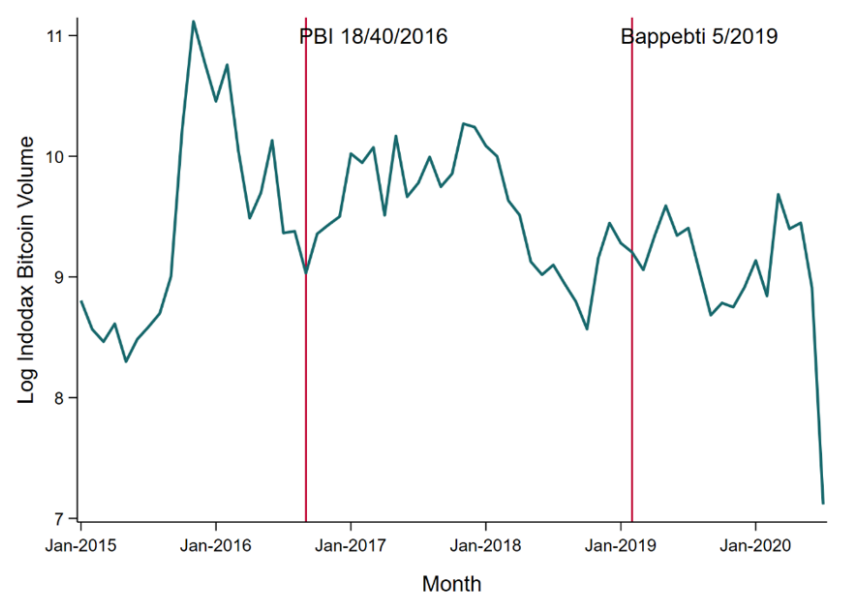

Figure 4: Bitcoin (Indodax) Trading Volume, 2015-2020 Source: Bitcoincharts.com, calculated by authors

Moreover, the addition of the trend variable also mitigates the risks of reporting spurious regression results.

Our regression results are reported in Table 2. Column (1) indicates the results derived from using CDS-6M as the CDS variable in our regression model, while Column (2) indicates the results derived from the CDS-12M measure. We include both types of CDS to test for the robustness of our findings. We observe five pivotal points from our regression analysis. First, in accordance with our initial hypothesis, we find that higher Bitcoin price is significantly associated with higher Bitcoin volumes. Higher asset prices imply higher returns, which further induce greater demand for the asset.

Second, both 6-M and 12-M CDS positive and significant coefficients indicate the relationship between conditions of uncertainty and Bitcoin demand in Indonesia. Higher values of CDS - which indicate higher domestic uncertainty - are associated with higher Bitcoin trading volume levels and demand in Indonesia. This finding is consistent with studies in other contexts as well. Mainly, an increase in Greece's economic uncertainty conditions is found to exert a positive impact on Bitcoin demand (Zamani \& Babatsikos, 2017). The same results are also observed among developed countries. A study by Panagiotidis et al. (2019) also empirically finds that periods of uncertainty significantly increase Bitcoin's demand (as implied by an increase in Bitcoin return) in Chinese, US, and European markets. However, we observe no significant association between global uncertainty, as proxied by the GEPU index, and market transaction volumes - albeit a positive sign is observed. This finding suggests that domestic market outcomes are more linearly related to their corresponding domestic condition than the global ones. 
Table 2: Regression Results

\begin{tabular}{lrr}
\hline \hline Variable & $(1)$ & $(2)$ \\
& Indodax Volume & Indodax Volume \\
\hline Log Bitcoin Price & $0.641^{* * *}$ & $0.645^{* * *}$ \\
& $(0.126)$ & $(0.126)$ \\
Log GEPU & 0.402 & 0.397 \\
& $(0.425)$ & $(0.416)$ \\
Log Gold & $-3.278^{* * *}$ & $-3.042^{* * * *}$ \\
& $(0.907)$ & $(0.857)$ \\
Log Kurs & $-16.55^{* * *}$ & $-16.94^{* * *}$ \\
& $(3.854)$ & $(4.043)$ \\
CDS 6M & $1.329^{* * *}$ & - \\
CDS 12M & $(0.259)$ & \\
$(0.283)$ & - & $1.390^{* * *}$ \\
Bappebti Policy Dummy & & \\
& 0.131 & -0.0283 \\
BI Policy Dummy $-0.327-0.333$ & $(0.230)$ & $(0.212)$ \\
& & \\
Trend & $(0.255)$ & $(0.256)$ \\
$(0.0182)(0.0191)$ & 0.0115 & 0.0146 \\
\hline Observation & & \\
\hline${ }^{*} \mathrm{p}<0.05,{ }^{* *} \mathrm{p}<0.01,{ }^{* * *} \mathrm{p}<0.001$ & 65 & \\
\hline
\end{tabular}

Third, the evidence indicates that increases in the exchange rate - implying depreciation of the Rupiah against the US Dollar - are associated with lower Bitcoin demand in Indonesia. One plausible mechanism by which such a negative association occurs is that as the value of the US dollar increases, so does the return on holding USD-denominated assets. This, in turn, pulls investors away from Bitcoin investments and subsequently reduces the total amount of Bitcoin volume being traded. Our result contradicts that of Panagiotidis et al. (2019), which empirically demonstrates that depreciation of the exchange rate has led to increases in Bitcoin demand in several developed markets such as China, the US, and Europe. We argue that there remains the possibility that exchange rate depreciation might yield different results among developing and developed countries. An important implication of this finding is that the observed negative relationship between exchange rate depreciation and Bitcoin demand further indicates that Bitcoin cannot be used as a hedge against Rupiah in the currency's depreciation. Fourth, the regression results suggest that the price and return of gold exhibit a negative and significant relationship (albeit at 5\%) with the demand for Bitcoin in Indonesia. This result implies that higher return for gold is associated with lower Bitcoin transaction volumes, validating our earlier conjecture of the two asset classes' substitutability.

Our fifth main result discusses the policy aspects of the Bitcoin market analysis. Contrary to our initial hypothesis, we observe no significant, robust statistical relationship between policy dummies and subsequent transaction volumes. We have tested these null findings under various specifications in which we assume 
Table 3: Additional Regression Results

\begin{tabular}{lrrrr}
\hline \hline \multirow{2}{*}{ Variable } & $(1)$ & $(2)$ & $(3)$ & $(4)$ \\
& 12-Months & 12-Months & 6-Months & 6-Months \\
Model & Model & Model & Model \\
\hline Log BTC Price & $0.537^{* * *}$ & $0.590^{* * *}$ & $0.589^{* * *}$ & $0.649^{* * *}$ \\
& $(0.115)$ & $(0.118)$ & $(0.116)$ & $(0.119)$ \\
Log GEPU & 0.324 & 0.328 & 0.387 & 0.404 \\
& $(0.436)$ & $(0.427)$ & $(0.433)$ & $(0.423)$ \\
Log Gold & $-2.984^{* *}$ & $-2.815^{* *}$ & $-3.191^{* *}$ & $-3.100^{* *}$ \\
& $(1.030)$ & $(1.003)$ & $(0.954)$ & $(0.914)$ \\
Log Kurs & $-15.00^{* * *}$ & $-15.56^{* * *}$ & $-15.41^{* * *}$ & $-16.08^{* * *}$ \\
& $(3.736)$ & $(3.856)$ & $(3.640)$ & $(3.842)$ \\
CDS 6M & $1.212^{* * *}$ & - & $1.242^{* * *}$ & \\
& $(0.214)$ & & $(0.224)$ & \\
CDS 12M & - & $1.332^{* * *}$ & & $1.351^{* * *}$ \\
Bappebti Policy Dummya & - & $(0.249)$ & & $(0.258)$ \\
BI Policy Dummy ${ }^{a}$ & -0.110 & -0.0656 & -0.182 & -0.172 \\
Trend & $(0.247)$ & $(0.254)$ & $(0.164)$ & $(0.169)$ \\
& 0.0116 & 0.00927 & 0.00944 & 0.00721 \\
& $(0.0173)$ & $(0.0172)$ & $(0.0162)$ & $(0.0162)$ \\
\hline Observation & 65 & 65 & 65 & 65
\end{tabular}

${ }^{a}$ The variable was omitted due to collinearity, a problem arising from the limited number of observations in our regression.

${ }^{*} \mathrm{p}<0.05,{ }^{* *} \mathrm{p}<0.01,{ }^{* * *} \mathrm{p}<0.001$

that any such policy-induced effects will only last for 12 and 6 months. The results of such tests are reported in Table 3. Columns (1) and (2) of Table 3 presents regression results using a 12-months policy dummy variable in an otherwise similar manner to that of Table 2.

In contrast, Columns (3) and (4) present the results using a 6-months policy dummy variable. It is important to note, however, that we are only able to test for the robustness of the BI policy variable $\left(d_{\text {usage }}\right)$ because, under various data limitations, the Bappebti policy dummy is to be omitted from the regression due to collinearity. We observe virtually no significant relationship between the policy dummies and market volumes in the subsequent period (6-12 months) under these additional specifications. This finding provides further evidence supporting the graphical interpretation mentioned earlier. We find little evidence that monetary policy implementation exerts influence on (or at the bare minimum, is associated with changes in) market outcomes.

Based on the results, we can conclude that there is strong evidence in favor of the existence of the 'flight-to-Bitcoin' phenomenon, pointing to the fact that Bitcoin has been used as an instrument for hedging during periods of global and domestic uncertainty. Bitcoin's utilization as a hedging instrument and safehaven can potentially raise a problem for the monetary policy-makers, partly because Bitcoin can be considered originating from private players. Besides, its blockchain business model also emphasizes the decentralization of the asset. As 
such, the government's control of such assets is strictly limited. Our analysis also establishes suggestive evidence that monetary policies in the last five years brought little to no changes in market outcomes. In addition, due to the substitutability nature between conventional and non-conventional asset classes, the proliferation of crypto-assets such as Bitcoin can also potentially pose disruption to existing financial markets. It might attract resources away from the more traditional assets within the country (e.g., securities and deposits).

Bitcoin's side function as a hedging instrument will pose adverse effects engendered by other hedging instruments in general. Excessive hedging efforts have decreased the money supply while also hampering economic growth and development (Le Long et al., 2013). Moreover, Bitcoin can also be categorized as a highly liquid asset because, in some countries, like Canada and Japan, Bitcoin is a legitimate means of payment. As a result, in the longer-term, Bitcoin's usage as a hedging instrument will arguably result in the outflow of assets from Indonesia to other countries, especially those acknowledging cryptocurrencies as the official means of payments.

\section{Conclusion}

Our study has attempted to study whether uncertainty, both globally and domestically, propels a rise in Indonesia's Bitcoin trading volume. Our analysis results suggest that during periods of domestic uncertainty, Bitcoin has been used by investors as an instrument of hedging. Both CDS measures' positive and significant coefficients, which proxy for domestic uncertainties. We argue that, when viewed through policy-makers' lens, the usage of Bitcoin as a hedging instrument might potentially bring about negative impacts. Incessant attempts at hedging by using Bitcoin might result in a decreased demand for domestic assets, while also triggering massive outflow movements of assets by investors abroad.

Interestingly, we observe that exchange rate depreciation is strongly associated with lower levels of demand for Bitcoin. Another plausible mechanism by which such a negative association occurs is through higher returns on other dollar-denominated assets, which further pulls investors away from Bitcoin investment. Moreover, this finding serves as an indication that Bitcoin has not been used as a hedging instrument during episodes of exchange rate depreciation. We can conclude that occurrences of exchange rate depreciation can serve as a counterbalancing force during times of higher (perceived) uncertainty to avoid Bitcoin's excessive use as a hedging instrument.

Our study also casts doubt on monetary policies' effectiveness in regulating the highly-decentralized nature of cryptocurrencies investment markets. We argue that it is crucial that the government, through monetary authorities, formulate policies, and exert limitations on Bitcoin transactions in Indonesia during periods of domestic uncertainty. Such control is needed to mitigate capital outflow risks and maintain stability during occurrences of turbulence within the financial system. One novel way of introducing control within the unconventional 
realm of digital currencies is for the central bank to develop its digital currency version. Such currencies are dubbed "Central Bank Digital Currencies" (CBDC) (Brunnermeier et al., 2019). CBDC can potentially serve essential functions in the financial system by:

1. providing means for the central bank to act as "lender of the last resort" within the digital currency realm, such as that of cryptocurrencies;

2. maintaining the uniformity of money, as such conditions might not necessarily be attained due to the availability of multiple large private players.

The broad macroeconomic effects of CBDC are theoretically limited (Niepelt, 2020), particularly if the issuing central bank opts to pass through the funds (obtained from issuing the CBDC) to the banking sectors, thus insulating these banks' balance sheets should their depositors choose to reallocate their funds from conventional deposits to CBDC. In addition to such limited macroeconomic effects, Niepelt (2020) shows that there are benefits that can be derived from it: increased competition within the payment industry, strengthened monetary policy transmission. Also, CBDC issuance helps maintain monetary sovereignty, which is crucial particularly if one considers the possibility that in the near future, as the digital payments issued by other monetary authorities or private players offer economic agents much more convenience or safety, agents may be incentivized to dump local currency.

Our study paves the way for future studies with regards to cryptocurrencies in the Indonesian context. There remain numerous possibilities for future avenues of research in this area. For instance, in this study, we only include one primary type of existing cryptocurrencies: Bitcoin, due to limitations on data availability. Future research can comprehensively analyze the broader 'flight-to-safety' phenomenon by including other primary types of cryptocurrencies such as Ether, Ripple, Litecoin, and Tether. In addition, future studies can also include analysis of the net benefits, if not loss, of the proliferation of cryptocurrency trading in Indonesia during the past decade. Specifically, one can start with Bitcoin's impact on conventional asset classes. Does Bitcoin crowd out investment in Indonesian conventional financial markets? Analysis of such equilibrium effects will prove to be fruitful, particularly for the monetary policy-makers, in leading the broader discourses on how to respond to the rapid development of cryptocurrency in Indonesia.

\section{References}

[1] Abadi, J., \& Brunnermeier, M. (2018). Blockchain economics. NBER Working Paper, 25407. National Bureau of Economic Research. https:/ /www.nber.org/papers/ w25407.

[2] Aysan, A. F., Demir, E., Gozgor, G., \& Lau, C. K. M. (2019). Effects of the geopolitical risks on Bitcoin returns and volatility. Research in International Business and Finance, 47, 511-518. doi: https://doi.org/10.1016/j.ribaf.2018.09.011.

[3] Balcilar, M., Bouri, E., Gupta, R., \& Roubaud, D. (2017). Can volume predict Bitcoin 
returns and volatility? A quantiles-based approach. Economic Modelling, 64, 74-81. doi: https://doi.org/10.1016/j.econmod.2017.03.019.

[4] Bappebti. (2019). Peraturan Badan Pengawas Perdagangan Berjangka Komoditi Nomor 5 Tahun 2019 tentang Ketentuan Teknis Penyelenggaraan Pasar Fisik Aset Kripto (Crypto Asset) di Bursa Berjangka. Jakarta: Badan Pengawas Perdagangan Berjangka Komoditi.

[5] Baur, D. G., \& Hoang, L. T. (2020). A crypto safe haven against Bitcoin. Finance Research Letters, 101431. doi: https://doi.org/10.1016/j.frl.2020.101431.

[6] Baur, D. G., Hong, K., \& Lee, A. D. (2018). Bitcoin: Medium of exchange or speculative assets?. Journal of International Financial Markets, Institutions and Money, 54, 177-189. doi: https://doi.org/10.1016/j.intfin.2017.12.004.

[7] Bouri, E., Molnár, P., Azzi, G., Roubaud, D., \& Hagfors, L. I. (2017). On the hedge and safe haven properties of Bitcoin: Is it really more than a diversifier?. Finance Research Letters, 20, 192-198. doi: https://doi.org/10.1016/j.frl.2016.09.025.

[8] Brunnermeier, M. K., James, H., \& Landau, J. P. (2019). The digitalization of money. NBER Working Paper, 26300. National Bureau of Economic Research. https:/ /www. nber.org/papers/w26300.

[9] Budish, E. (2018). The economic limits of bitcoin and the blockchain. NBER Working Paper, 24717. National Bureau of Economic Research. https:/ / www.nber.org/papers / w24717.

[10] Catalini, C., \& Gans, J. S. (2019). Some simple economics of the blockchain. NBER Working Paper, 22952. National Bureau of Economic Research. https://www.nber. org/papers/w22952.

[11] Chan, W. H., Le, M., \& Wu, Y. W. (2019). Holding Bitcoin longer: The dynamic hedging abilities of Bitcoin. The Quarterly Review of Economics and Finance, 71, 107-113. doi: https://doi.org/10.1016/j.qref.2018.07.004.

[12] Chang, S. E. (2018). Legal status of virtual currency in Indonesia in the absence of specific regulations. Indonesia Law Review, 8(3), 328-348. doi: http://dx.doi.org/10.15742/ilrev.v8n3.485.

[13] Cheng, H. P., \& Yen, K. C. (2020). The relationship between the economic policy uncertainty and the cryptocurrency market. Finance Research Letters, 35, 101308. doi: https://doi.org/10.1016/j.frl.2019.101308.

[14] Cong, L. W., \& He, Z. (2019). Blockchain disruption and smart contracts. The Review of Financial Studies, 32(5), 1754-1797. doi: https://doi.org/10.1093/rfs/hhz007.

[15] Das, D., Le Roux, C. L., Jana, R. K., \& Dutta, A. (2020). Does Bitcoin hedge crude oil implied volatility and structural shocks? A comparison with gold, commodity and the US Dollar. Finance Research Letters, 36, 101335. doi: https://doi.org/10.1016/j.frl.2019.101335.

[16] Dyhrberg, A. H. (2016). Hedging capabilities of bitcoin. Is it the virtual gold?. Finance Research Letters, 16, 139-144. https://doi.org/10.1016/j.frl.2015.10.025.

[17] European Central Bank. (2012). Virtual Currency Schemes, October 2012. https: / www. ecb.europa.eu/pub/pdf/other/virtualcurrencyschemes201210en.pdf.

[18] Fang, L., Bouri, E., Gupta, R., \& Roubaud, D. (2019). Does global economic uncertainty matter for the volatility and hedging effectiveness of Bitcoin?. International Review of Financial Analysis, 61, 29-36. doi: https://doi.org/10.1016/j.irfa.2018.12.010.

[19] Gurdgiev, C., \& O'Loughlin, D. (2020). Herding and anchoring in cryptocurrency markets: Investor reaction to fear and uncertainty. Journal of Behavioral and Experimental Finance, 25, 100271. doi: https://doi.org/10.1016/j.jbef.2020.100271.

[20] He, D., Habermeier, K., Leckow, R., Haksar, V., Almeida, Y., Kashima, M., ... 
Verdugo-Yepes, C. (2016). Virtual Currencies and Beyond: Initial Considerations. IMF Staff Discussion Note, SDN/16/03. International Monetary Fund. doi: https://doi.org/10.5089/9781498363273.006.

[21] Iqbal, J. (2017). Does gold hedge stock market, inflation and exchange rate risks? An econometric investigation. International Review of Economics $\mathcal{E}$ Finance, 48, 1-17. doi: https://doi.org/10.1016/j.iref.2016.11.005.

[22] Jones, A. T., \& Sackley, W. H. (2016). An uncertain suggestion for gold-pricing models: the effect of economic policy uncertainty on gold prices. Journal of Economics and Finance, 40(2), 367-379. doi: https:/ /doi.org/10.1007/s12197-014-9313-3.

[23] Klein, T., Thu, H. P., \& Walther, T. (2018). Bitcoin is not the New Gold-A comparison of volatility, correlation, and portfolio performance. International Review of Financial Analysis, 59, 105-116. doi: https://doi.org/10.1016/j.irfa.2018.07.010.

[24] Kroll, J. A., Davey, I. C., \& Felten, E. W. (2013). The economics of bitcoin mining, or bitcoin in the presence of adversaries. The Twelfth Workshop on the Economics of Information Security (WEIS 2013), Washington, DC, June 11-12, 2013. http:/ / weis2013.econinfosec.org/papers/KrollDaveyFeltenWEIS2013.pdf.

[25] Le Long, H., De Ceuster, M. J. K., Annaert, J., \& Amonhaemanon, D. (2013). Gold as a hedge against inflation: The Vietnamese case. Procedia Economics and Finance, 5, 502-511. doi: https://doi.org/10.1016/s2212-5671(13)00059-2.

[26] Meiklejohn, S., Pomarole, M., Jordan, G., Levchenko, K., McCoy, D., Voelker, G. M., \& Savage, S. (2013). A fistful of bitcoins: characterizing payments among men with no names. IMC '13: Proceedings of the 2013 Conference on Internet Measurement Conference, 127-140. doi: https://doi.org/10.1145/2504730.2504747.

[27] Niepelt, D. (2020, 03 February). Digital money and central bank digital currency: An executive summary for policymakers. VOX, CEPR Policy Portal. https://voxeu.org/ article/digital-money-and-central-bank-digital-currency-executive-summary.

[28] Panagiotidis, T., Stengos, T., \& Vravosinos, O. (2018). On the determinants of bitcoin returns: A LASSO approach. Finance Research Letters, 27, 235-240. doi: https://doi.org/10.1016/j.frl.2018.03.016.

[29] Panagiotidis, T., Stengos, T., \& Vravosinos, O. (2019). The effects of markets, uncertainty and search intensity on bitcoin returns. International Review of Financial Analysis, 63, 220-242. doi: https://doi.org/10.1016/j.irfa.2018.11.002.

[30] Raskin, M., Saleh, F., \& Yermack, D. (2019). How do private digital currencies affect government policy? NBER Working Paper, 26219. National Bureau of Economic Research. https://www.nber.org/papers/w26219.

[31] Reboredo, J. C., \& Rivera-Castro, M. A. (2014). Can gold hedge and preserve value when the US dollar depreciates?. Economic Modelling, 39, 168-173. doi: https://doi.org/10.1016/j.econmod.2014.02.038.

[32] Richter, C., Kraus, S., \& Bouncken, R. B. (2015). Virtual currencies like Bitcoin as a paradigm shift in the field of transactions. International Business $\mathcal{E}$ Economics Research Journal (IBER), 14(4), 575-586. doi: https://doi.org/10.19030/iber.v14i4.9350.

[33] Roth, F. (2009). The effect of the financial crisis on systemic trust. Intereconomics, 44(4), 203-208. doi: https:/ /doi.org/10.1007/s10272-009-0296-9.

[34] Scharfstein, D. S., \& Stein, J. C. (1990). Herd behavior and investment. The American Economic Review, 80(3), 465-479. doi: https:/ /www.jstor.org/stable/2006678.

[35] Selmi, R., Mensi, W., Hammoudeh, S., \& Bouoiyour, J. (2018). Is Bitcoin a hedge, a safe haven or a diversifier for oil price movements? A comparison with gold. Energy Economics, 74, 787-801. doi: https://doi.org/10.1016/j.eneco.2018.07.007. 
[36] Smales, L. A. (2019). Bitcoin as a safe haven: Is it even worth considering?. Finance Research Letters, 30, 385-393. doi: https://doi.org/10.1016/j.frl.2018.11.002.

[37] Truby, J. (2018). Decarbonizing Bitcoin: Law and policy choices for reducing the energy consumption of Blockchain technologies and digital currencies. Energy Research E Social Science, 44, 399-410. doi: https://doi.org/10.1016/j.erss.2018.06.009.

[38] Wallace, B. (2011, November 23). The rise and fall of Bitcoin. wired.com. https: / /www. wired.com/2011/11/mf-bitcoin/.

[39] Wolfson, S. N. (2015). Bitcoin: the early market. Journal of Business \& Economics Research (JBER), 13(4), 201-214. doi: https://doi.org/10.19030/jber.v13i4.9452.

[40] Wu, S., Tong, M., Yang, Z., \& Derbali, A. (2019). Does gold or Bitcoin hedge economic policy uncertainty?. Finance Research Letters, 31, 171-178. doi: https://doi.org/10.1016/j.frl.2019.04.001.

[41] Yermack, D. (2013). Is Bitcoin a real currency? An economic appraisal. NBER Working Paper, 19747. National Bureau of Economic Research. https:/ /www.nber.org/papers / w19747.

[42] Yermack, D. (2017). Corporate governance and blockchains. Review of Finance, 21(1), 7-31. doi: https://doi.org/10.1093/rof/rfw074.

[43] Yu, Y. G., \& Zhang, J. (2020, October 26). Flight to Bitcoin.https://ssrn.com/abstract= 3278469.

[44] Zamani, E. D., \& Babatsikos, I. (2017). The use of bitcoins in light of the financial crisis: The case of Greece. MCIS 2017 Proceedings, 5. The 11th Mediterranean Conference on Information Systems (MCIS), Genoa, Italy, 2017. https:/ / aisel.aisnet.org/mcis2017/ $5 /$. 


\section{Appendix}

\section{Testing for the Stationarity of the Variables}

The stationarity of each independent variable reported in Table A1. The p-values of each independent variable at the corresponding lags are reported in the table. It is also important to note that we include three lags in the following test. The results derived from further suggest that all independent variables possess unit root and are not stationary over time.

Table A1: Stationarity Testing at Level

\begin{tabular}{cccccc}
\hline \hline Lags & Log.BTC Price & Log.GEPU & Log.GOLD & Log.KURS & Log.CDS \\
\hline L1 & 0.837461 & 0.067787 & 0.092659 & 0.008668 & 0.047962 \\
L2 & 0.851985 & 0.100569 & 0.534470 & 0.360517 & 0.140396 \\
L3 & 0.784340 & 0.259084 & 0.930471 & 0.269060 & 0.386957 \\
\hline
\end{tabular}

The graphical representations of the non-stationary properties of each variable are observed in the following graphs:
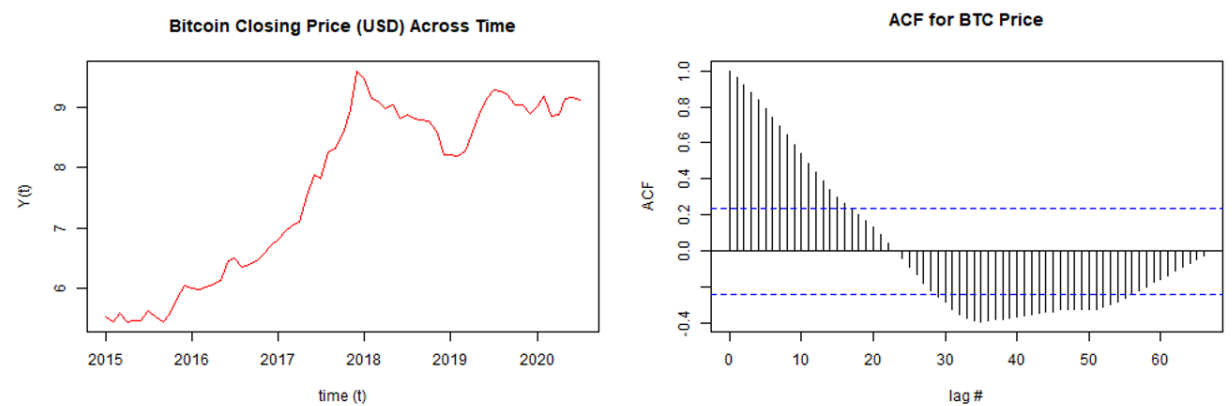

Figure A1: Time Trend of BTC Price 

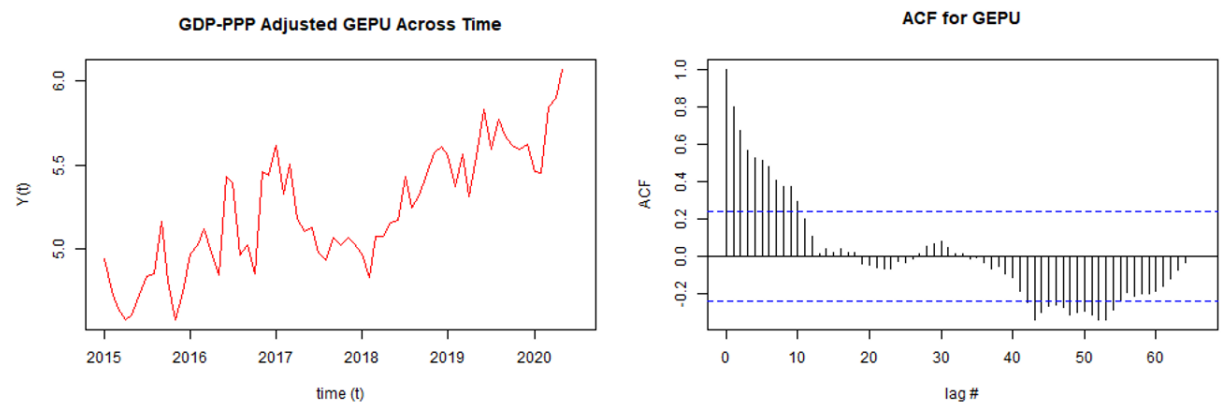

Figure A2: Time Trend of GEPU
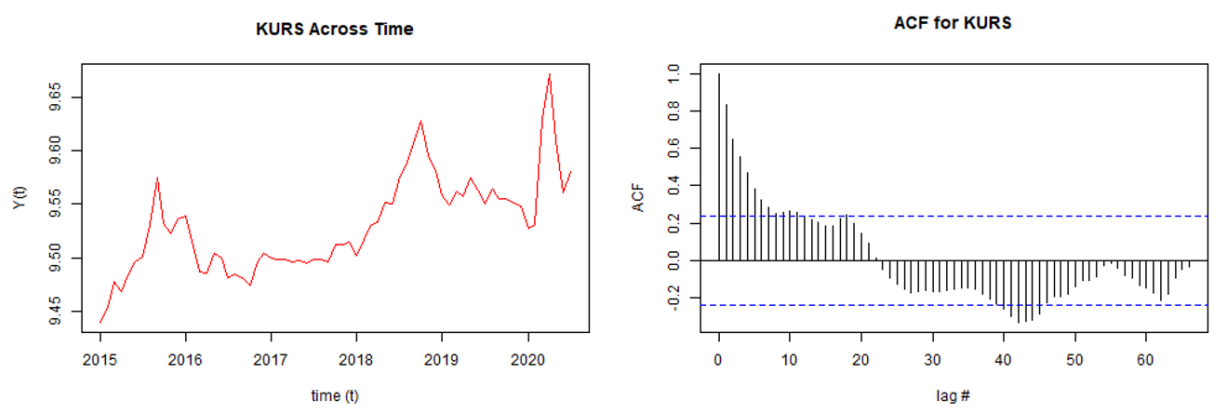

Figure A3: Time Trend of KURS
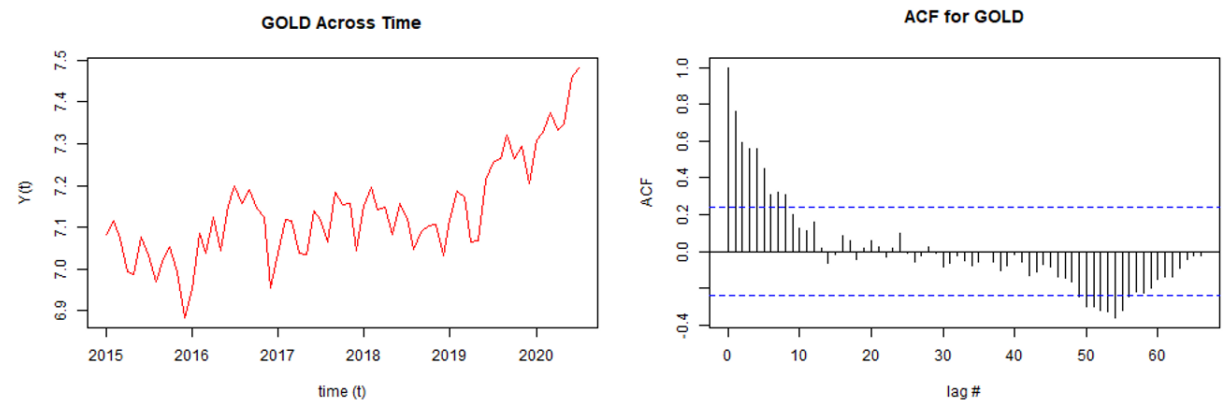

Figure A4: Time Trend of GOLD 

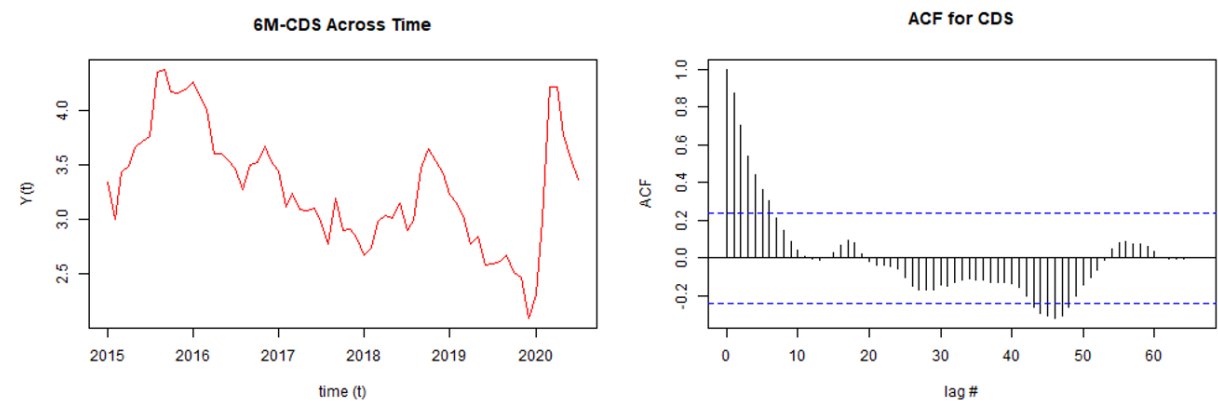

Figure A5: Time Trend of CDS 6M
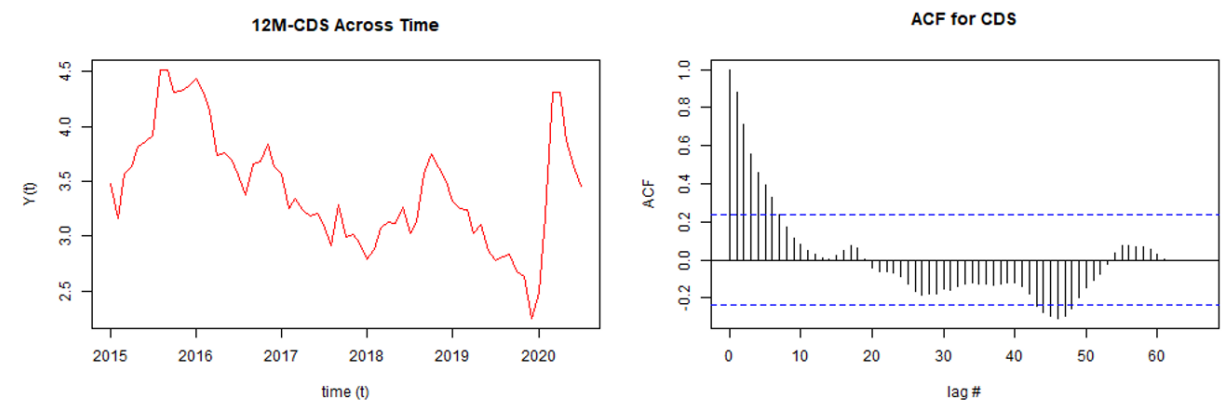

Figure A6: Time Trend of CDS 12M 